\title{
A Theory-Based Discussion of
}

\section{International Technology Funding}

\author{
Michael Hübler ${ }^{\dagger}$ \\ Hannover Economic Papers (HEP) No. 550 \\ ISSN 0949-9962
}

April 2014

\begin{abstract}
Climate policy negotiations identified international technology funding as a means of achieving carbon emissions reductions in developing countries. Such funds are now being realized. This paper is probably the first theory-based discussion of international technology funding. It sets up a Ramsey model of a developing economy including imports of capital and embodied technologies from abroad. Going beyond a scale, technique and composition effect, it disentangles five resulting economic effects and four technology-related policy levers and their interactions. It then discusses their role in designing an international technology fund with the aim to reduce emissions efficiently. The paper concludes that it is inefficient to address emissions reductions independent of the technological absorptive capacity and other aspects of economic development. Therefore, it opts for an integrated technology funding scheme.
\end{abstract}

JEL Classifications: F21, O11, O33, O47

Keywords: technology fund, climate policy, economic development

\footnotetext{
${ }^{*}$ The responsibility for the contents of this discussion paper rests with the author. Note that discussion papers are preliminary. Please check the final version that appeared in Environmental Economics and Policy Studies, 2015, 17(2), 313-327, Springer, http://link.springer.com/article/10. 1007/s10018-014-0099-5?sa_campaign=email/event/articleAuthor/onlineFirst. - I thank Marian Leimbach, Andreas Löschel, Petra Prasse, Daiju Narita, Gernot Klepper, Sonja Peterson, Egle Tafenau, Johannes Bröcker, Christian Flachsland and Steffen Brunner for very helpful advice and support.

${ }^{\dagger}$ Corresponding author, email: huebler@iuw.uni-hannover.de, tel: +49-511-762-19569, fax: +49511-762-2667, Leibniz Universität Hannover, Institute for Environmental Economics and World Trade, Königsworther Platz 1, 30167 Hannover, Germany; Centre for European Economic Research (ZEW); Potsdam Institute for Climate Impact Research (PIK); Kiel Institute for the World Economy (IfW).
} 


\section{Introduction}

The carbon emissions reductions that avoid severe detrimental impacts of climate change require emissions reductions in developing and emerging countries. As long as there is no worldwide carbon pricing scheme, climate policy can attempt to reduce emissions by supporting investments that transfer advanced technologies to developing countries. Even with a global carbon pricing scheme, such support can ease market-based technology diffusion. A commitment for financial and technological support for developing countries by industrialized countries can also convince developing countries to join a carbon pricing scheme. Therefore, plans for supporting and governing energy investments and technology transfer have been frequently proposed (Bali Roadmap, 2007; Copenhagen Accord, 2009; Cancún Summit, 2010) and worked out. In particular, international transfers amounting to 100 billion US-\$ per annum by 2020 were ambitiously proposed (compare UNFCCC, 2010). Currently, technology funding schemes are being introduced (for example Climate Investment Funds, 2014; for a critical comparison with the UNFCCC framework: Haughey, 2009; for an overview: Climate Funds Update, 2014). Technology funding can principally occur via grants, loans and guarantees for potentially energy saving investment projects.

Because technology funding policies are in their early phase, it is still open how technology funding will work out and how an economically efficient design of a technology funding mechanism looks like. It is also open to what extent and for what purposes developing countries will in theory make use of technology funding and what the outcomes in terms of technical progress, economic development and emissions will be. This paper addresses these research issues. A better understanding of these issues can help design technology funding schemes in such a way that the likelihood of achieving the desired policy effects - in particular emissions reductions and economic growth - increases.

For this purpose, this paper sets up a 'Ramsey type' model of intertemporally optimal investment for a developing country as a small open economy. Besides using domestically created capital, the country can buy capital from abroad. 'Abroad' means in particular from industrialized countries. Different to domestic capital, foreign capital embodies advanced technologies that create technology spillovers. There are two types of spillovers: an output increasing and a carbon emissions reducing spillover. They work in opposite directions in terms of total emissions. Increasing output raises carbon 
emissions by assuming that production requires energy and energy generation requires fossil fuel inputs. Nonetheless, the output increasing spillover is inevitable for economic development. - Going beyond a scale, technique and composition effect (Antweiler et al. 2001), the socially optimal solution of this model shows that buying capital from abroad generates in total five effects: (1) Productive capital: Capital as a production factor increases output. (2) Productive technology: The embodied technologies increase output (positive side effect of capital use and externality in case of spillovers to other firms). (3) Emitting capital: The use of capital additionally requires the use of fossil fuel inputs that generate carbon emissions. (4) Emitting technology: Since technologies increase output, they will indirectly also increase fossil fuel use and thus emissions (negative externality of capital use). (5) Abating technology: The embodied technologies reduce the volume of emissions generated by a given volume of capital or output (positive side effect and spillover externality of capital use). These effects are derived from the first-order conditions of the model solution. This paper then identifies four technology-related policy levers that make use of these five effects with the aim to enhance technology spillovers: (1) Emissions intensity of energy supply. (2) Energy efficiency of production. (3) Macroeconomic absorptive capacity. (4) Microeconomic absorptive capacity. It shows how these effects and levers are interconnected. Each single policy lever (for example a reduction in the emissions intensity of energy supply via low-carbon technologies) is due to diminishing returns and hampered by other factors that are insufficiently developed (for example infrastructure as a determinant of absorptive capacity). Based on these insights, it opts for an integrated technology funding scheme that takes all these aspects listed above into account rather than solely focusing on one aspect.

Such an integrated technology funding scheme has so far not been considered in the Clean Development Mechanism (CDM) or in technology funding schemes. Against this backdrop, it appears to be important from a policy as well as a theory perspective to study international technology funding. Although technology funding has recently gained such a high relevance, scholars have hardly theoretically examined technology funding schemes. There are, however, comprehensive reports addressing climate change, economic development, international financing and technology transfer (IPCC, 2000; OECD, 2002; World Bank, 2006, 2008, 2010; climate finance: Levi et al., 2010; climate funding: OECD, 2010; innovation and technology diffusion: UNFCCC, 2010). And 
there are numerous (1) theoretical, (2) numerical, (3) econometric, and (4) innovation system studies that address issues related to international technology spillovers. The following references can only provide a brief overview of related literature strands:

(1) The theoretical literature on (endogenous) growth covers international technology spillovers (for textbook versions: Acemoglu, 2009, chapter 18; Aghion and Howitt, 2009, chapter 7) and technical change that can be directed towards clean and dirty technologies or sectors (Acemoglu et al., 2011). More specifically, some theoretical contributions have studied the complex interaction of international technology spillovers with different carbon pricing schemes (Golombeck and Hoel, 2005, 2008, 2011). A recent theoretical contribution examines international cooperation on technological development as an alternative to international cooperation on emissions reductions (El-Sayed and Rubio, 2014). It shows that, under specific assumptions, a coalition engaged in technological cooperation consists of three to six members.

(2) Innovation and international technology diffusion have been acknowledged as being important for numerical climate policy modeling and thus been implemented in a number of Computable General Equilibrium (CGE) models (Popp, 2004; Kemfert, 2005; Otto et al., 2008; Hübler, 2011; Kypreos and Turton, 2011) and numerical growth models (Edenhofer et al., 2005; Bosetti et al., 2008; Leimbach and Baumstark, 2010; Hübler et al., 2012). In this literature endogenous innovation and imitation (international technology spillovers) usually have some potential to reduce climate policy costs.

(3) Numerous econometric studies examine technology spillovers via FDI and trade in general (for example Aitken and Harrison, 1999; Javorcik, 2004; for overviews: Blomström and Kokko, 1998; Saggi, 2002; Keller, 2004; Hoekman and Javorcik, 2006) and a few in particular with respect to energy and emissions savings (Cole, 2006; Perkins and Neumayer, 2009; Hübler and Keller, 2010) with mixed results. A few studies find energy efficiency improvements via Official Development Assistance (ODA) (Hübler and Keller, 2010; Kretschmer et al., 2013). Moreover, technology transfer is found to occur via the Clean Development Mechanism (CDM) (De Coninck et al., 2007).

(4) A large number of studies describes processes of innovation and technology diffusion in form of innovation systems that encompass system functions (for example Hekkert et al., 2007; Hekkert and Negro, 2009). A 'system of innovation' describes the 'determinants of innovation processes', this means "all important economic, social, po- 
litical, organizational, institutional, and other factors that influence the development, diffusion, and use of innovations" (Edquist, 2005). More specifically, they distinguish the functions 'entrepreneurial activities', 'knowledge development (learning)', 'knowledge diffusion through networks', 'guidance of the search', 'market formation', 'resource mobilisation', and 'creation of legitimacy/counteract resistance to change' (Hekkert and Negro, 2009). Some studies particularly focus on the evolution of (renewable) energy technology systems (for instance Jacobsen and Bergek, 2004; Healey and Bunting, 2008). Finally, the literature on technological transitions examines "socio-technical regimes, niches and landscapes, which form the basis of a so-called multi-level framework to study the transformation of regimes" (Markard and Truffer, 2008).

This paper fills the lack of theoretical thinking about technology funding at least to some extent: It sets up and analyzes an intuitive, stylized Ramsey type model of economic growth in Section 2. It discusses the different effects and policy levers and their interactions in Section 3. It derives policy conclusions and discusses future research in Section 4.

\section{Model}

This section sets up a Ramsey type growth model that allows for intertemporally optimal capital accumulation. It examines a small ${ }^{1}$ open developing economy called Home. While domestic investment is not associated with technological advances, buying capital from the international market brings about inflows of advanced technologies. ${ }^{2}$ These advanced technologies expand the output produced by using a given volume of production inputs and they reduce the carbon emissions stemming from a given capital input and output volume. Technologies are assumed to diffuse through Home over time. In this sense, there exists an international and national (across firms and private and public consumers) technology spillover. Carbon emissions exacerbate climate change as a global bad that negatively affects Home (as well as the rest of the world which is not taken into account here). In the following, we will analytically derive conditions that

\footnotetext{
${ }^{1}$ The economy does not influence world market prices.

${ }^{2}$ These international capital flows can be interpreted as Foreign Direct Investment (FDI).
} 
characterize the socially optimal inflow of foreign capital.

Home, a small open developing economy, maximizes her welfare subject to constraints:

$$
\begin{aligned}
\max _{\{i(t), x(t)\}} \mathfrak{W} & =\max _{\{i(t), x(t)\}} \int_{0}^{\infty} e^{-[\rho-\eta] t} u(c(t)) d t, u_{c}(t)>0, u_{c c}(t)<0 \\
c(t) & =f(t)-i(t)-\nu x(t)-d(t) \\
f(t) & =f(A(t), k(t)), f_{A}(t)>0, f_{k}(t)>0, f_{k k}(t)<0 \\
d(t) & =d(S(t)), d_{S}(t)>0, d_{S S}(t)>0 \\
\dot{k}(t) & =i(t)+x(t)-\delta k(t) \\
\dot{A}(t) & =T(A(t), x(t))-\tau A(t), T_{A}(t)<0, T_{x}(t)>0, T_{x x}(t)<0 \\
\dot{S}(t) & =E(A(t), f(t))-\sigma S(t), E_{A}(t)<0, E_{f}(t)>0
\end{aligned}
$$

Latin capital letters denote variables in total values, Latin lower case letters denote variables in per capita terms. Subscripts denote partial derivatives with respect to the variable indicated. Greek letters denote parameters. $u$ is utility, which the representative consumer draws from consumption $c$. $f$ denotes production, $i$ investment which can be taken from output in a one-to-one fashion. A represents technology, $k$ capital, $d$ climate change damages, $S$ the carbon stock in the atmosphere. $x$ denotes foreign capital inflows, and $\nu$ denotes the corresponding price of one unit of foreign capital. $T$ describes the technology spillover, that is the increase in technological knowledge $A$ transferred through capital inflow $x$. $E$ denotes carbon emissions stemming from production. Utility increases in consumption in a concave form. Production increases in capital input in a concave form as well. Climate damages increase in emissions in a convex form. The technology spillover increases in capital inflows in a concave fashion. Referring to the literature on 'distance to the technology frontier' (going back to the seminal work by Nelson and Phelps, 1966) and cross-country convergence (c.f. the literature reviewed in the Introduction), the technology spillover's strength decreases in the technology level already achieved.

$\rho$ is the time discount rate, $\eta$ the population growth rate, $\delta$ and $\tau$ are the depreciation rates of capital and technological knowledge. $\sigma$ captures carbon decay in the atmosphere 
due to ocean uptake. The price for domestic capital is implicitly normalized to one because output can directly be transferred into capital via investment. Imposing a nonarbitrage condition for domestic versus foreign capital would drag down the price for foreign capital to one, too. However, foreign capital differs from domestic capital with respect to the associated knowledge spillovers on production $f$ and on resulting emissions $E$. This means that capital inflows help expand output (in production) generated from a certain capital volume and generate technology spillovers across firms. They also help reduce emissions (in the energy system and elsewhere in production and consumption) generated from a certain capital or output volume and generate technology spillovers as well. The technology spillovers in production and the energy system also include changes in the sectoral composition that can increase or decrease output and emissions. Herein, an emissions increase through foreign capital inflows is basically also possible in the absence of a carbon price in Home. As a consequence of these external effects of foreign capital $x, \nu$ can in general differ from one. We capture a scale $[f(k), E(f(k)), E(f(A))]$, technique $[f(A), E(A)]$ and composition effect $^{3}[f(A), E(A)]$ of capital and technology transfer (Antweiler et al., 2001) with regard to output and emissions. Finally, we assume initial values for the stock variables: $k(0), A(0)$, and $S(0)$.

To solve the optimization problem, we set up the Current Value Hamiltonian:

$$
\begin{aligned}
\mathfrak{H} & =u(f(A(t), k(t))-i(t)-\nu x(t)-d(S(t)))+\mu^{k}(t)[i(t)+x(t)-\delta k(t)] \\
& +\mu^{A}(t)[T(A(t), x(t))-\tau A(t)]+\mu^{S}(t)[E(A(t), f(A(t), k(t)))-\sigma S(t)]
\end{aligned}
$$

The first-order conditions read: $\frac{\partial \mathfrak{H}(t)}{\partial i(t)}=0, \frac{\partial \mathfrak{H}(t)}{\partial x(t)}=0, \quad \frac{\partial \mathfrak{H}(t)}{\partial k(t)}=[\rho-\eta] \mu^{k}(t)-\dot{\mu}^{k}(\mathrm{t})$, $\frac{\partial \mathfrak{H}(t)}{\partial A(t)}=[\rho-\eta] \mu^{A}(t)-\dot{\mu}^{A}(t)$, and $\frac{\partial \mathfrak{H}(t)}{\partial S(t)}=[\rho-\eta] \mu^{S}(t)-\dot{\mu}^{S}(t)$.

The full-fledged first-order conditions are laid out in the Appendix. $\mu^{k}$ is the shadow price for capital investment. $\mu^{A}$ is the shadow price for technology spillovers that increase output. $\mu^{S}$ is the shadow price for carbon emissions taking technology spillovers

\footnotetext{
${ }^{3}$ When we view the aggregate production function as a combination of sectoral production functions, sectoral changes will affect the technology of the aggregate production function in a similar way as technical progress.
} 
into account that decrease emissions. $\mu^{S}$ can be externally given by the world carbon price in the presence of a global carbon pricing scheme. Alternatively, $\mu^{S}$ expresses the (shadow) carbon price in terms of the marginal climate change damage in Home. In the equations above we assume in general that a carbon price has not yet been introduced in Home and is to be taken into account in our considerations of capital-related effects.

The transversality conditions for the problem read: $\lim _{t \rightarrow \infty}\left[e^{-[\rho-\eta] t} \mu^{k}(t) k(t)\right]=0$, $\lim _{t \rightarrow \infty}\left[e^{-[\rho-\eta] t} \mu^{A}(t) A(t)\right]=0$, and $\lim _{t \rightarrow \infty}\left[e^{-[\rho-\eta] t} \mu^{S}(t) S(t)\right]=0$.

In the following, we assume that a stable steady state exists where all time derivatives are zero and examine its economic properties. ${ }^{4}$ We drop time indices referring to steady state values. Equated to zero, Equations (5) to (7) directly provide the following straightforward insights: In the steady state, capital investments from domestic and foreign sources match depreciation. Technical advances match the depreciation of existing technological knowledge, and carbon emissions match carbon depreciation through ocean uptake.

The following optimality conditions can be derived from the first-order conditions through mathematical reformulations. They characterize the steady state and constitute the social optimum for Home:

$$
\begin{gathered}
1=f_{k}(\rho-\eta+\delta)^{-1}\left(1+\mu^{S} u_{c}^{-1} E_{f}\right) \\
\nu=\underbrace{f_{k}(\rho-\eta+\delta)^{-1}}_{\nu^{k}}+\underbrace{f_{A} T_{x}\left(\rho-\eta-T_{A}+\tau\right)^{-1}}_{\nu^{A}} \\
\underbrace{+\mu^{S} u_{c}^{-1} E_{f} f_{k}(\rho-\eta+\delta)^{-1}}_{\nu^{k E}} \underbrace{+\mu^{S} u_{c}^{-1} E_{f} f_{A} T_{x}\left(\rho-\eta-T_{A}+\tau\right)^{-1}}_{\nu^{A E}} \\
\underbrace{+\mu^{S} u_{c}^{-1} E_{A} T_{x}\left(\rho-\eta-T_{A}+\tau\right)^{-1}}_{\nu^{A S}} \\
\mu^{S}=-u_{c} d_{S}[\rho-\eta+\sigma]^{-1} \leq 0
\end{gathered}
$$

While Equation (9) characterizes the optimal capital stock with respect to domestic

\footnotetext{
${ }^{4}$ Saddle path stability of international capital transfer associated with international technology diffusion in a similar model of intertemporal optimization has been shown by Hübler and Lontzek (2011).
} 
investment $i$, Equation (10) characterizes the optimal capital stock with respect to foreign capital inflows $x$. Equation (10) includes expression (9) plus additional terms stemming from technology spillovers. Due to technology spillovers, the price for capital inflows $\nu$ in general differs from the implicit price for domestic investment equal to one, $\nu \neq 1$.

The market solution for domestic investment, in which the economic agents do not internalize the negative climate change externality, can easily be derived from Equation (9) by setting $\mu^{S}=0$. This results in the standard optimality condition $f_{k}=\rho-\eta+\delta .{ }^{5}$ In the same vein, the market solution for foreign capital for the case that economic agents do neither internalize the negative climate change externality nor the positive technology externalities can be derived from Equation (10): We set all $\mu$ multipliers (shadow prices) in Equation (8) to zero so that Equation (10) diminishes to $\nu=f_{k}(\rho-\eta+\delta)^{-1}=: \nu^{k}$ which is equal to one by comparison with Equation (9) $1=f_{k}(\rho-\eta+\delta)^{-1}$ with $\mu^{S}=0$. This means, neglecting all technology- and emissions-related effects, the price for domestic capital determines the equilibrium price for foreign capital. Yet a firm will be willing to pay a price $\nu>1$ for foreign capital if there is evidence for a higher productivity of foreign capital than of domestic capital within the same firm (independent of spillovers across firms).

Home's government will be willing to pay a price $\nu \neq 1$ knowing that the various externalities exist. Since there are positive as well as negative externalities, it is not clear-cut whether the $\nu$ is larger or lower than one. However, exactly reaching the social optimum as characterized by Equations (10) and (11) requires the introduction of a subsidy or tax in order to internalize the combination of the positive and negative externalities. Let us in the following discuss the net subsidyf or foreign capital $\nu-1=\nu^{A}+\nu^{k E}+\nu^{A E}+\nu^{A S}$ encompassing all subsidies and taxes that address the different externalities. Let us leave it open for the moment who finances the net subsidy and simply assume that Home's government imposes and finances it via a lump-sum transfer taken from the representative consumer (from $c(t)$ ). In the next section we will analyze and discuss each term $\left(\nu^{k}, \nu^{A}, \nu^{k E}, \nu^{A E}, \nu^{A S}\right)$ in Equation (10) regarding

\footnotetext{
${ }^{5}$ With $\mu^{S}=0$ and the price for domestic capital implicitly set to one, because output is directly transferred into capital via investment, and under the assumption that the representative consumer still behaves in a forward looking fashion and takes population growth into account.
} 
the meaning for technology funding.

\section{Discussion}

This section first analyzes the socially optimal steady state. It second analyzes policy levers regarding their effect on output and emissions in the steady state. These effects and levers are all examined as marginal effects under optimality.

Equation (10) characterizes the optimal use of foreign capital $x$ which can be decomposed into five effects:

(1) Productive capital $\nu^{k}$ : Capital as a production factor simply increases output. This is the standard effect present in any growth model and also present in Equation (9) that describes the optimal use of domestic capital. Private investors take this effect already into account within the market solution. Thus, we need not discuss it any further regarding policy measures.

(2) Productive technology $\nu^{A}$ : The technologies embodied in foreign capital additionally increase output in production. This can be a positive side effect of capital use that private investors take into account. In this case, it is not to be addressed by policy either. It can also capture technology spillovers across (foreign and domestic) firms and public and private agents and thus represent a positive externality. In this case, private investors do not take it into account so that it is to be internalized via a subsidy by capital-related policy, for example within a technology funding scheme. Let us in the following assume that the latter case of technology spillovers prevails.

(3) Emitting capital $\nu^{k E}$ : Given today's production technologies as assumed in the model, the use of capital additionally requires the use of energy and thus fossil fuel inputs that generate carbon emissions and thus a negative externality through climate change damages. If a carbon price is in place in Home, this effect will be internalized regarding domestic capital (the second term in Equation 9) as well as foreign capital (in Equation 10). If not - which is our assumption here - an optimal capital-related policy needs to take this negative externality into account via a tax. If energy supply were completely carbon-free, this effect would vanish.

(4) Emitting technology $\nu^{A E}$ : Since the technologies embodied in foreign capital 
also increase output, they will indirectly also increase fossil fuel use and thus emissions. This again results in a negative externality that capital-related policy needs to take into account via a tax in the absence of carbon pricing in Home. If energy supply were completely carbon-free, this effect would vanish, too.

(5) Abating technology $\nu^{A S}$ : The embodied technologies reduce the volume of emissions generated by a given volume of capital or output. This creates a positive side effect of capital use that investors will only take into account in the presence of a carbon price. As in the case of the productive technology effect, there can also be technology spillovers across (foreign and domestic) firms and public and private agents that create a positive externality. Assuming that there is no carbon pricing scheme installed in Home, capital-related policy needs to internalize this external effect via a subsidy. ${ }^{6}$ While the productive technology effect refers mainly to the production and consumption of goods, the abating technology effect mainly refers to energy or electricity generation - this means to the decarbonization of energy supply - and to transportation.

The above effects (2) to (5) form the overall net subsidy introduced before. We are now going to explore which levers policy makers can use to influence output and emissions via the five effects described above. This means we assume that certain factors in Equation (10) can be influenced.

(1) Foreign capital $x$ : The policy lever of main interest in the context of international technology funding is the volume of foreign capital $x$. Let us for the moment assume that Home internalizes all external effects of $x$ so that Home's social optimum is reached given a certain price $\nu$ for $x$. To model technology funding, let us now assume that external foreign policy makers can exogenously increase (or in general change) this volume by lowering the price $\nu$. Then the term $\nu^{k}$ describes the standard effect that a lower price $\nu$ allows for a lower marginal product of capital $f_{k}$ so that the use of $k$ increases and output as well. ${ }^{7}$ The spillover decreases in the existing technology level via $T_{A}<0$ while approaching the technology frontier. ${ }^{8}$ Regarding term $\nu^{A}$, we rule out the case that the technology spillover reduces output since we have assumed that

\footnotetext{
${ }^{6}$ Under the assumption that foreign capital reduces emissions via technology transfer.

${ }^{7}$ Note that population growth $\eta$ must not exceed the time discount rate $\rho$ so that the effects have the normal direction as in standard growth models.

${ }^{8} \mathrm{~A}$ higher existing technology level acts like a higher time discount rate in reducing the value of the technology spillover.
} 
output rises in technology $\left(f_{A}>0\right)$ and technology transfer and spillovers increase in the volume of transferred capital $\left(T_{x}>0\right)$. Thus, a lower $\nu$ allows for exploiting the marginal benefit of $x$ for raising $T$ to a larger extent (a lower $T_{x}$ due to a larger volume $x$ ). As a result, output $f$ rises directly via capital accumulation and indirectly via the technology spillover.

The more interesting effect is that on emissions: Emissions will only decrease with more $x$ if $\left(E_{f} f_{k}+E_{f} f_{A} T_{x}\right)+E_{A} T_{x}<0$ with $E_{A}<0$. This means when the emissions increase through the output increase - directly via capital and indirectly via technology - is smaller than the emissions reduction via technology. Hence, those who govern the technology fund will require this information in order to predict the effect of $x$ on total emissions. The net subsidy with respect to the emissions externality will only be positive if $\nu^{k E}+\nu^{A E}+\nu^{A S}>0$. Otherwise, the capital transfer will be taxed in terms of carbon emissions.

(2) Carbon price $\mu^{s}$ : In the presence of a (global) carbon pricing scheme, in which Home participates, $\mu^{s}$ will be given. If $\mu^{s}$ rises, the three mitigation channels $\nu^{k E}, \nu^{A E}$ and $\nu^{A s}$ will be simultaneously used in the optimal case. How much each channel will be used depends on the marginal benefit that each channel yields given by the terms $\nu^{k E}, \nu^{A E}$ and $\nu^{A s}$. If Home does not participate in a carbon pricing scheme, $\mu^{s}$ will be given by the marginal damage of climate change created in Home as expressed by Equation (11).

Besides the two general levers listed above, we can identify four directly technologyrelated levers:

(1) Emissions intensity of energy supply $E_{A}$ : It determines how strong the decarbonization of energy supply and energy use resulting from the transferred technology is. It can in particular be raised by selecting low-carbon technologies for the technology transfer. Among the effects listed above, it affects only the abating technology effect. It has been the main channel of the Clean Development Mechanism (CDM) so far and will probably be the focus of technology funding. It is the 'safest' lever in the sense that raising $E_{A}$ via a wise selection of low-carbon technologies inevitably reduces emissions. Nonetheless, it is economically inefficient to make solely use of this lever: First, there is a diminishing marginal benefit of doing so. Second, it is well-known that the improvement in the efficiency of energy use offers important (relatively cheap) reduction options. 
(2) Energy efficiency of production $E_{f}$ : Energy efficiency and as a result emissions efficiency are in this model captured by the term $E_{f}$ that appears in the emitting capital term $\nu^{k E}$ and in the emitting technology term $\nu^{A E}$. Lowering $E_{f}$ can thus mitigate the direct and indirect (through technology) emissions increase via foreign capital use. It can be achieved by selecting low-energy technologies such as energy efficient machines. It acts as an alternative to $E_{A}$, although being different: Due to the rebound effect represented by the factors $f_{k}$ and $f_{A},{ }^{9}$ it is not evident that raising $E_{f}$ will lower emissions in total. This is especially true in the absence of a carbon price in Home.

(3) Macroeconomic absorptive capacity $T_{x}: E_{A}$ and $E_{f}$ both interact with the overall ability to gain technological advances from foreign capital $x$ and to let them diffuse within the economy. Thus, the effectiveness of the decarbonization lever and the energy efficiency lever can be enhanced by improving $T_{x}$, the macroeconomic absorptive capacity. This can be achieved by improving education, infrastructure, media, the political and legal system etc. Nonetheless, besides supporting the decarbonization of the economy within $\nu^{A S}, T_{x}$ also enhances the output and thus the emissions expansion through technology transfer within the productive technology effect $\nu^{A}$ and the emitting technology effect $\nu^{A E}$. This lever is especially important with respect to the longer-term development of Home: Low-carbon and low-energy machinery may have a strong shortrun effect. But the development of Home towards an economy that can create and apply such technologies on its own requires a stronger macroeconomic capability $T_{x}$ to do so.

(4) Microeconomic absorptive capacity $f_{A}$ : The latter two effects also interact with the ability of firms and other economic agents to translate the acquired technologies into output expansions. Although one might attempt to lower $f_{A}$ with respect to emissions, it is certainly desirable ro raise $f_{A}$ with respect to output expansion (and thus increased consumption and economic development). Raising $f_{A}$ requires the improvement of education and skills of workers as well as the use of other technologies that ease the implementation of new technologies.

In summary, having disentangled various policy effects and levers, we notice that they are strongly interconnected when looking at the multiplicative terms in Equation (10). It is economically inefficient to make solely use of one effect or lever. Hence, a

\footnotetext{
${ }^{9}$ A higher energy efficiency leads to more energy use.
} 
technology funding scheme designed by foreign countries aiming at economic efficiency needs to take all aspects simultaneously into account. Furthermore, suppose that foreign capital is provided to the developing Home country without any control mechanism. Then Home could likewise make use of all these channels aiming at the optimal capital use described above. But different distracting interests challenge the achievement of the optimal solution. (Discussing the misuse of capital in terms of abuse of political power, corruption, violence etc. is beyond the scope of this theoretical analysis, though.) Likeise, it appears questionable that those who govern a technology fund can fully select technologies and fully control the use of technologies in Home. Another important insight of the analysis is that it is ambiguous whether the positive or the negative externalities associated with foreign capital prevail. Thus, it is ambiguous whether a price $\nu>1$ or $\nu<1$, i.e. a higher or lower price for foreign 'technology fund' capital than for 'usual' domestic capital, is socially optimal. For all these reasons, it appears to be crucial to think about and evaluate the effects laid out above when designing technology funding policies.

\section{Conclusion}

We have set up and studied a Ramsey model of domestic and foreign capital accumulation in a developing economy in the presence of a climate change externality. Foreign capital creates output enhancing and carbon emissions reducing technology externalities. We have identified five effects of foreign capital accumulation: the productive capital, productive technology, emitting capital, emitting technology, and abating technology effect. Therein, we have identified four technology-related levers that economic policy may use: the emissions intensity of energy supply, energy efficiency of production, macroeconomic absorptive capacity, and microeconomic absorptive capacity.

What can we learn from this analysis regarding the design of a technology fund? Focusing solely on one of these effects and policy levers will likely be economically inefficient: First, each option is ceteris paribus subject to diminishing returns or marginal benefits on investment. Second, the effects and levers strongly interact. Third, it is not evident that foreign capital inflows should receive an overall subsidy and not a tax 
(because of a prevailing climate change externality). Thus, investment using one lever can crepitate when an interconnected lever is insufficient. Moreover, there is the risk that investments in low-energy and low-carbon technologies deploy an effective shortrun effect but not an effective long-run effect. The latter is inevitable for economic development and requires investments in the macroeconomic (and the firm-specific) absorptive capacity. There is also the risk that funding is misused for projects that would have been carried out anyway or that will not deploy the desired positive macroeconomic and environmental effects. These insights are in accordance with case studies on 'policy aimed at facilitating low carbon technology transfer to developing countries' (Ockwell et al., 2008). Different to the innovation systems and system functions literature, the results are derived from a theoretical model of economic growth. This model type cannot take social, political, organizational, institutional, engineering-based, or informationflow-based aspects explicitly into account. In this model, the interaction of effects and policy levers occurs only within the economic sphere.

Notwithstanding, the model results can be interpreted with respect to policy implications. They suggest an integrated multi-dimensional technology funding scheme that takes the discussed effects and policy levers simultaneously into account. This could be achieved by evaluating each effect and lever, possibly with the help of a scoring scheme. If two levers are complementary, funding should address both. Focusing on one promising lever could be inefficient and waste resources. Instead, country-specific weaknesses regarding technology diffusion and adoption and absorptive capacity on the macro- and microeconomic level should be identified and addressed. Such an integrated multi-dimensional funding scheme goes far beyond asking the question whether an investment project can achieve an emissions reduction (relative to whatever benchmark) or not (as in the Clean Development Mechanism). It considers aspects of long-term development via technology adoption and diffusion. It attempts to identify weaknesses in the economy, for example in terms of infrastructure, the legal system and education. It then distributes the funding among the relevant levers. In this sense 'green' funding becomes directly related to development aid addressing poverty, education, infrastructure and the like.

However, the model that we have discussed is a stylized Ramsey growth model. We have only looked at the steady state characteristics ignoring the transition to the 
steady state. Future research could look deeper into these dynamics. Theoretical future research could also analyze optimal technology funding from the viewpoint of a developed donor economy rather than a developing recipient economy. A numerical model implementation could attempt to quantify the capital flows and effects that we have identified. Applied future research could work out the specific criteria and the scoring scheme for the integrated technology assessment.

\section{References}

Acemoglu, D. (2009). Introduction to Modern Economic Growth. Princeton University Press, New Jersey, USA.

Acemoglu, D., P. Aghion, L. Bursztyn and D. Hemous (2011). The Environment and Directed Technical Change. American Economic Review, 102(1), 131-166.

Aghion, P. and P. Howitt (2009). The Economics of Growth. The MIT Press, Cambridge, USA.

Aitken, B.J. and A.E. Harrison (1999). Do domestic firms benefit from direct foreign investment? Evidence from Venezuela. The American Economic Review, 89(3), 605-618.

Antweiler, W., B.R. Copeland and M.S. Taylor (2001), Is Free Trade Good for the Environment? American Economic Review, 91(4), 877-908.

Blomström, M. and A. Kokko (1998). Multinational Corporations and Spillovers. Journal of Economic Surveys, 12(3), 247-277.

Bosetti, V., C. Carraro, E. Massettia and M. Tavoni (2008). International energy R\&D spillovers and the economics of greenhouse gas atmospheric stabilization. Energy Economics, 30(6), 2912-2929.

Climate Investment Funds (2014). http://www.climateinvestmentfunds.org/cif/.

Climate Funds Update (2014). http://www.climatefundsupdate.org/listing.

Cole, M.A. (2006). Does trade liberalization increase national energy use? Economics Letters, 92, 108-112.

De Coninck, H., F. Haake and N. van Der Linden (2007). Technology transfer in the Clean Development Mechanism. Climate Policy, 7(5), 444-456. 
Edenhofer, O., N. Bauer and E. Kriegler (2005). The impact of technological change on climate protection and welfare: Insights from the model MIND. Ecological Economics, $54,277-292$.

Edquist, C. (2005). Systems of Innovation - Perspectives and Challenges In: The Oxford Handbook of Innovation, edited by J. Fagerberg, D.C. Mowery and R.R. Nelson 181-208, Oxford University Press, Oxford, UK and New York, USA.

El-Sayed, A. and S.J. Rubio (2014). Sharing R\&D Investments in Cleaner Technologies to Mitigate Climate Change. FEEM Nota di Lavoro 41.2014.

Golombek, R. and M. Hoel (2005). Climate Policy under Technology Spillovers. Environmental and Resource Economics, 31, 201-227.

Golombek, R. and M. Hoel (2008). Endogenous Technology and Tradable Emission Quotas. Resource and Energy Economics, 30, 197-208.

Golombek, R. and M. Hoel (2011). International Cooperation on Climate-friendly Technologies. Environmental and Resource Economics, 49, 473-490.

Haughey, A. (2009). The World Bank Clean Technology Fund: Friend or Foe to the UNFCCC? Sustainable Development Law \& Policy, Climate Law Reporter, 9(2), 19.

Healey, G. and A. Bunting (2008). Wind Power in Australia: Overcoming Technological and Institutional Barriers. Bulletin of Science Technology and Society, 28, 115-127.

Hekkert, M.P., R.A.A. Suurs, S.O. Negro, S. Kuhlmann and R. Smits (2007). Functions of innovation systems: A new approach for analysing technological change. Technological Forecasting and Social Change, 74(4), 413-432.

Hekkert, M.P. and S.O. Negro (2009). Functions of innovation systems as a framework to understand sustainable technological change: Empirical evidence for earlier claims. Technological Forecasting and Social Change, 76(4), 584-594.

Hoekman, B., and B.S. Javorcik, eds. (2006). Global integration \& technology transfer. The World Bank, Washington, DC, USA.

Hübler, M. and A. Keller (2010). Energy savings via FDI? Empirical evidence from developing countries. Environment and Development Economics, 15(1), 59-80.

Hübler, M. (2011). Technology Diffusion under Contraction and Convergence: A CGE Analysis of China. Energy Economics, 33(1), 131-142.

Hübler, M. and T. Lontzek (2011). Socially Optimal North-South Capital Transfer and Technology Diffusion. Forthcoming in: The Journal of International Trade and Economic Development.

Hübler, M., L. Baumstark, M. Leimbach, O. Edenhofer and N. Bauer (2012). An Inte- 
grated Assessment Model with Endogenous Growth. Ecological Economics, 83, 118-131.

IPCC (2000). Methodological and Technological Issues in Technology Transfer. http://www.ipcc-wg3.de/publications/special-reports/.

Jacobsson, S. and A. Bergek (2004). Transforming the energy sector: the evolution of technological systems in renewable energy technology. Industrial and Corporate Change, 13(5), 815-849.

Javorcik, B.S. (2004). Does foreign direct investment increase the productivity of domestic firms? In search of spillovers through backward linkages. The American Economic Review, 94 (3), 605-627.

Keller, W. (2004). International Technology Diffusion. Journal of Economic Literature, Journal of Economic Literature, 42(3), 752-782.

Kemfert, C. (2005). Induced technological change in a multi-regional, multi-sectoral, integrated assessment model (WIAGEM) Impact assessment of climate policy strategies. Ecological Economics, 54, 293-305.

Kretschmer, B., M. Hübler and P. Nunnenkamp (2013). Does Foreign Aid Reduce Energy and Carbon Intensities of Developing Economies? Journal of International Development, 25(1), 67-91.

Kypreos, S. and H. Turton (2011). Climate change scenarios and Technology Transfer Protocols. Energy Policy, 39, 844-853.

Leimbach, M. and L. Baumstark (2010). The impact of capital trade and technological spillovers on climate policies. Ecological Economics, 69, 2341-2355.

Levi, M.A., E.C. Economy, S.K. O'Neil and A. Segal (2010). Energy Innovation Driving Technology Competition and Cooperation Among the U.S., China, India, and Brazil. Council on Foreign Relations, New York, USA.

Markard, J. and B. Truffer (2008). Technological innovation systems and the multi-level perspective: Towards an integrated framework. Research Policy, 37, 596-615.

Nelson, R. and E. Phelps (1966). Investment in Humans, Technological Diffusion, and Economic Growth. The American Economic Review, Papers and Proceedings, 61, 69-75.

Ockwell, D.G., J. Watson, G. MacKerron, P. Pal and F. Yamin (2008). Key policy considerations for facilitating low carbon technology transfer to developing countries. Energy Policy, 36(11), 4104-4115.

OECD (2002). Foreign Direct Investment for Development - Maximising Benefits, Minimising Costs, Paris, France.

OECD (2010). Development Perspectives for a Post-2012 Climate Financing Architec- 
ture. http://www. oecd.org/greengrowth/green-development/47115936.pdf

Otto, V.M., A. Löschel and J. Reilly (2008). Directed Technical Change and Differentiated Climate Policy. Energy Economics, 30(6), 2855-2878.

Perkins and Neumayer (2009). Transnational Linkages and the Spillover of EnvironmentEfficiency into Developing Countries. Global Environmental Change, 19(3), 375-383.

Popp, D. (2004). ENTICE: endogenous technological change in the DICE model of global warming. Journal of Environmental Economics and Management, 48, 742-768.

Saggi, K. (2002). Trade, Foreign Direct Investment, and International Technology Transfer: A Survey. World Bank Research Observer, Oxford University Press, 17(2), 191-235.

UNFCCC (2010). Report of the Secretary-General's High-level Advisory Group on Climate Change Financing. http://climateblue.org/2010/12/.

World Bank (2006). Global Development Finance - The Development Potential of Surging Capital Flows. Washington DC, USA.

World Bank (2008). Global Economic Prospects - Technology Diffusion in the Developing World. Washington DC, USA.

World Bank (2010). World Development Report 2010 - Development and Climate Change. Washington DC, USA. 


\section{Appendix}

The full-fledged first-order conditions read:

$$
\begin{array}{lcl}
\frac{\partial \mathfrak{H}}{\partial i}= & -u_{c}+\mu^{k} & =0 \\
\frac{\partial \mathfrak{H}}{\partial x}= & -u_{c} \nu+\mu^{k}+\mu^{A} T_{x} & =0 \\
\frac{\partial \mathfrak{H}}{\partial k}= & u_{c} f_{k}-\mu^{k} \delta+\mu^{s} E_{f} f_{k} & =[\rho-\eta] \mu^{k}-\dot{\mu}^{k} \\
\frac{\partial \mathfrak{H}}{\partial A}= & u_{c} f_{A}+\mu^{A}\left(T_{A}-\tau\right)+\mu^{s}\left(E_{A}+E_{f} f_{A}\right) & =[\rho-\eta] \mu^{A}-\dot{\mu}^{A} \\
\frac{\partial \mathfrak{H}}{\partial S}= & -u_{c} d_{S}-\mu^{S} \sigma &
\end{array}
$$

Equation (12) directly yields an expression for $\mu^{k}$ that replaces $\mu^{k}$ in (13) and (14). Equation (13) then yields an expression for $\mu^{A}$ that is inserted in (15). The time derivatives of $\mu^{k}, \mu^{A}$ and $\mu^{S}$ disappear in the steady state. Then (14) leads to (9), (15) leads to (10), and (16) directly leads to (11). The summand 'one' in (10) is replaced by the expression for 'one' given by (9). 